\title{
Adult height of prepubertal short children born small for gestational age treated with GH
}

Myriam Rosilio, Jean-Claude Carel $^{1}$, Emmanuel Ecosse ${ }^{1}$ and Jean-Louis Chaussain ${ }^{1}$ on behalf of the 0908 Lilly Study Group

Lilly Research Laboratories, Eli Lilly and Company, Suresnes, France and ${ }^{1}$ Groupe Hospitalier Cochin-Saint Vincent de Paul, Université Paris V, 75014 Paris, France

(Correspondence should be addressed to M Rosilio, Lilly France 13 rue Pagès, 92158 Suresnes, Cedex, France; Email: rosilio_myriam@lilly.com)

\begin{abstract}
Objective: Human GH (hGH) treatment leads to catch-up growth in children with short stature born small for gestational age (SGA). However, long-term efficacy and safety results in this patient group remain scarce. The present study assessed the efficacy and safety of late childhood treatment with biosynthetic hGH (Humatrope) in a group of short children born SGA (height $<-2$ standard deviation scores (SDS)).

Design: Patients in this open-label, Phase III, multicenter study received a daily hGH dose of $0.067 \mathrm{mg} / \mathrm{kg}$ for 2 years, and then received no treatment for the following 2 years. After the fourth year on study, patients whose height had decreased more than 0.5 SDS but who still showed growth potential based on bone age were allowed to resume treatment until they reached adult height.

Methods: Height gain SDS was assessed for 11 girls and 24 boys (mean age \pm S.D. $9.6 \pm 0.9$ years) at the end of the 2 years of hGH treatment, during the subsequent 2-year off-treatment period, and upon reaching adult height.

Results: At the end of the initial 2-year treatment period, $83 \%$ of patients had reached a height within the normal range, with a mean increase in height SDS vs baseline of $1.3 \pm 0.3(P<0.001)$. Adult heights $(n=20)$ were within the normal range for $50 \%$ of patients, and mean height gain from baseline was statistically significant $(0.7 \pm 0.8$ SDS, $P<0.001)$. Fasting glucose and glycosylated hemoglobin levels were not significantly modified during treatment.

Conclusions: High-dose hGH treatment for a minimum of 2 years in short children born SGA was well tolerated and resulted in a significant increase in adolescent and adult height.
\end{abstract}

European Journal of Endocrinology 152 835-843

\section{Introduction}

Among infants born small for gestational age (SGA), $40-53 \%$ catch up in weight before 6 months of age $(1,2)$. Catch-up in height, on the other hand, may take up to 2 years (3). Eight to 10 percent of children born SGA fail to reach a height within the normal range by the age of 2 years (4). As a result of this failure of catch-up growth, adult height is likely to be below target height $(\mathrm{TH})$ in these patients $(1-3,5)$. In a Swedish cohort of children born SGA, the mean adult height of those with heights still below -2 SDS (standard deviation scores, adjusted for age and gender) at the age of 2 years was 1.84 SDS $(12.1 \mathrm{~cm})$ lower than that of those with a height above -2 SDS at the same age (6).

Clinical trials aimed at improving the growth of short children born SGA using human growth hormone
(hGH) have been conducted. Short- to mid-term studies have demonstrated that catch-up growth can be induced by hGH administration, with height gains ranging from 1.1 to 2.6 SDS depending on the age of the children at treatment initiation, the hGH dosage used, and the duration of hGH therapy $(7-13)$. However, the pattern of hGH administration is still a matter of debate, as some authors favor continuous treatment (10) while others favor discontinuous treatment (9). Long-term results on adult height are scarce and discordant, with height gains ranging from 0.1 to 1.8 SDS in this patient group (14-18).

In the exploratory study reported here, we hypothesized that hGH treatment in short children born SGA, begun near the start of puberty and continued for 2 years, would lead to a sufficient height gain at pubertal entry, and that the pubertal growth spurt 
would then enable these patients to maintain the treatment benefit and increase adult height.

\section{Patients and methods}

The present open-label, Phase III, multicenter study was designed to assess the efficacy and safety of biosynthetic hGH (Humatrope, somatropin; Eli Lilly \& Company, Suresnes, France) in a group of short children born SGA. The study was approved by the ethics committee of Paris Cochin prior to study initiation, and informed consent was obtained for each child participating in the trial. The study extended from April 1991 (first patient assigned to therapy) to September 2001 (last patient completed study).

\section{Study inclusion/exclusion criteria}

The following inclusion criteria applied: chronological age (CA) 7 to $<9$ years for girls and 9 to $<11$ years for boys; height below -2 S.D. (19); bone age (BA) less than or equal to CA (20); birth length below - 2 S.D. for gestational age (21); duration of pregnancy $>36$ weeks; parental height $>$ or $=160 \mathrm{~cm}(-2.5$ S.D.) for the father and $>$ or $=147 \mathrm{~cm}(-2.9$ S.D. $)$ for the mother (19); growth documented by two or three measurements during the 2 years prior to the study; and a normal response to a GH stimulation test. Patients were not included if they had previously received GH treatment or if they had any chronic disease or malformation.

\section{Treatment protocol}

hGH was administered to all patients s.c. at a dose of $0.067 \mathrm{mg} / \mathrm{kg}$ per day (equivalent to $0.2 \mathrm{IU} / \mathrm{kg}$ per day) for 2 years, and treatment was then discontinued for the next 2 years; the period between initiation of hGH therapy and the end of the off-treatment period will henceforth be referred to as 'Period I'. After the fourth year on study, patients who lost more than 0.5 SDS in height during the 2 year off-treatment period and who still presented growth potential $(\mathrm{BA}<12$ years for girls or $<14$ years for boys) were allowed to resume hGH treatment at the same dose; the period between the point at which hGH treatment could be resumed and the last height measurement will henceforth be referred to as 'Period II'. Patients were followed, whether they had resumed treatment or not, until they reached adult height, defined as a height velocity $\leq 1 \mathrm{~cm} /$ year using two subsequent measurements taken at least 6 months apart (19), and/or BA $\geq 16$ years for girls or $\geq 18$ years for boys (22). If BA was not assessed at the last height measurement, the time from the last $\mathrm{BA}$ to the last height measurement was added to the last BA to derive an estimated BA (23, 24). Adult height SDS was calculated either based on normative values for a $\mathrm{CA}$ of 18 years (referred to as SDS/age 18), regardless of the patient's actual CA at the time of adult height measurement, or as SDS/CA when actual CA was taken into consideration.

\section{Data collected}

BA reading was performed centrally according to the method of Greulich \& Pyle (20). Predicted height was calculated according to the method of Bayley \& Pinneau (22). Pubertal development was evaluated according to the Tanner classification, and pubertal onset was defined as stable Tanner stage B2 for girls or Tanner stage G2 for boys (25). Insulin-like growth factor-I (IGF-I) was assayed centrally after acid/ethanol extraction at the Fondation de Recherche en Hormonologie (Fresnes, France). Mean normal IGF-I values for boys were $0.61 \mathrm{IU} / \mathrm{ml}$ for ages $8-10$ years and $0.88 \mathrm{IU} / \mathrm{ml}$ for ages $10-14$ years. Mean normal IGF-I values for girls were $0.69 \mathrm{IU} / \mathrm{ml}$ for ages $8-10$ years and $1.28 \mathrm{IU} / \mathrm{ml}$ for ages $10-14$ years. Fasting glucose and glycosylated hemoglobin (HbA1c) determinations were performed locally at each study center. Normal values ranged from 3.3 to $6.1 \mathrm{mmol} / \mathrm{l}$ for fasting glucose and 3.9 to $6.5 \%$ for HbAlc.

\section{Patient disposition (Fig. 1)}

During study Period I, 35 patients (11 girls and 24 boys) recruited from seven centers in France were treated with hGH for 2 years. Of these patients, five presented with protocol violations: one patient did not meet the birth length criterion of $<-2$ S.D. for gestational age (birth length $=-1.44$ SDS); two patients did not meet the parental height criterion (one father's height was unknown, and one mother's height was equal to $146 \mathrm{~cm}$ ); one patient presented with cardiac disease; and one patient had constitutional bone disease that was diagnosed later during the study. However, as we performed an intent-to-treat analysis, all those patients were kept in the efficacy and safety analyses.

Of the 35 patients, 29 continued on and completed the subsequent 2 year off-treatment period. During study Period II, seven patients resumed hGH therapy, while 17 were followed up without resuming therapy. For 20 of these patients (four who resumed hGH therapy and 16 who did not), adult height was obtained and analyzed at the end of the study. Fifteen patients were not included in the analysis for adult height for the following reasons: 12 were lost to follow-up during either Period I or II and were without documented adult height; one was excluded from the study because of prescription of gonadotropin-releasing hormone agonists; one discontinued from the study due to parental decision; and one was still growing at the time of final evaluation. As the latter two patients' 


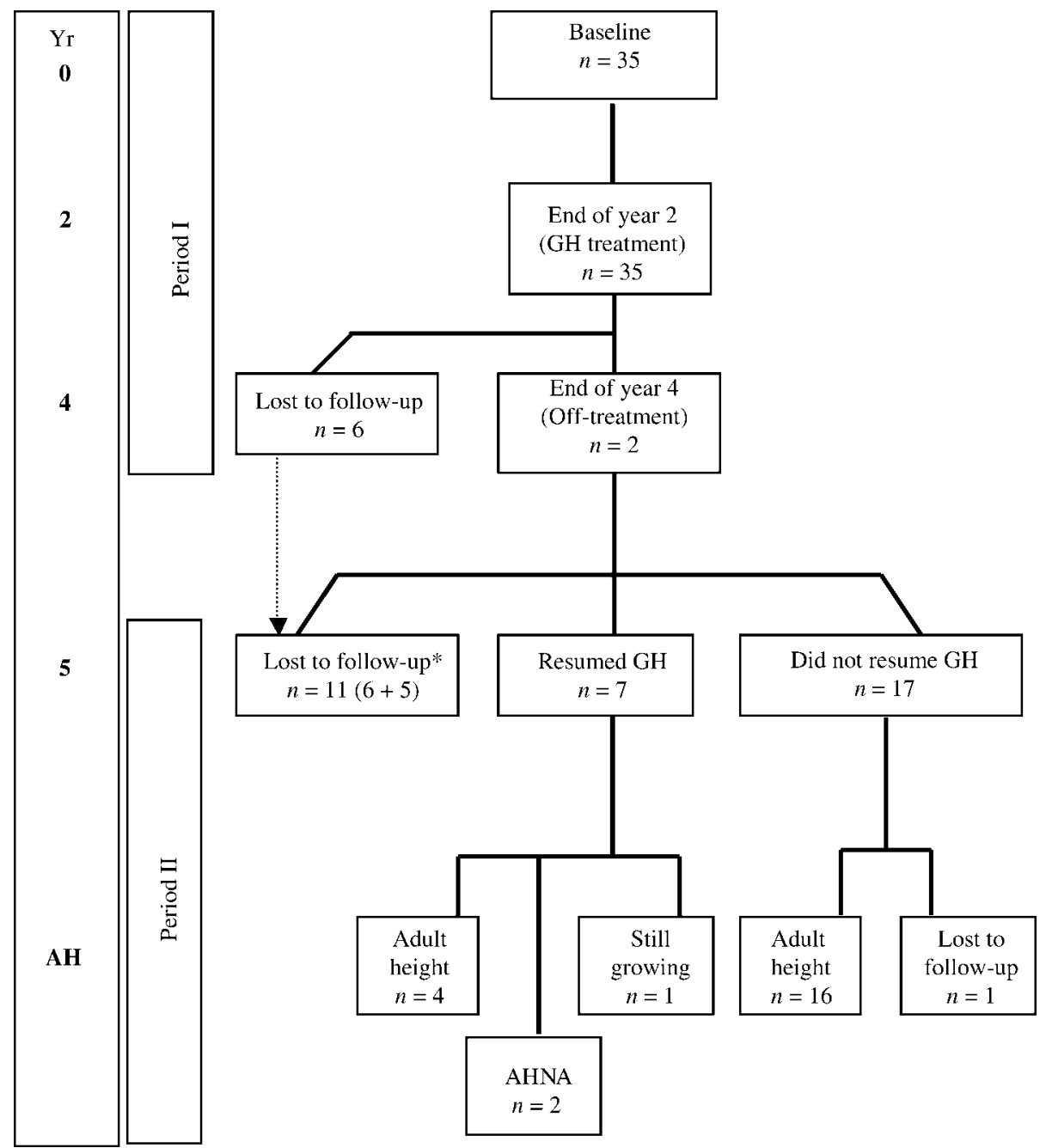

Figure 1 Patient disposition. $\mathrm{Yr}=$ follow-up year; $\mathrm{AH}=$ adult height, $\mathrm{AHNA}=$ adult height not available. *Cumulative number of patients lost to follow-up including the six lost between the end of treatment years 2 and 4 . adult heights were not documented, they have been included in the 'lost to follow-up' group on Fig. 1 for simplicity.

\section{Data analysis}

TH was calculated according to the method proposed by Ranke to account for assortative mating (26). Parental adjusted height SDS was calculated as the difference between actual height SDS and TH SDS.

Statistical evaluations were performed using the SAS 8.1 statistical package. Continuous data are summarized by number of values, mean, s.D., minimum and maximum. Categorical data are presented as numbers and percentages. For normally distributed variables, comparisons were made using a paired $t$-test. Otherwise, comparisons were made using the signed-rank statistic.

Three linear multiple regression models were developed to explain height gain in SDS at three endpoints, using demographic and auxological information as independent variables. Before each multivariate analysis, bivariate analyses, in which Pearson's correlation coefficient $r, r^{2}$, and significance of relationship $(P)$ were calculated to select potential variables for the models, were performed.

The first model was developed using a step-wise backward regression with an $\alpha$ risk of 0.25 . This value was used instead of the commonly used 0.05 due to the low number of observations $(n=35)$.

Inspection of the distribution of Cook's statistic (27) was performed to detect each observation's influence on the estimated parameter. In cases of outlier observations distorting the model, these observations were excluded and a new model was evaluated.

\section{Results}

\section{Period I}

Height changes during Period I Patients' characteristics at birth and baseline are summarized in Table 1. During Period I, all patients received daily hGH therapy for 2.3 \pm 0.1 years (range: 2.1-2.6 years). 
Table 1 Patients' characteristics at birth and at baseline $(n=35)$.

\begin{tabular}{lrc}
\hline Variable & Mean \pm S.D. & Range (min; max) \\
\hline Birth length (SDS*) & $-3.0 \pm 0.8$ & $-4.8 ;-1.4$ \\
Birth weight (SDS $\left.{ }^{*}\right)$ & $-1.6 \pm 0.9$ & $-3.8 ; 0.8$ \\
Gestational age (weeks) & $39.5 \pm 1.4$ & $37 ; 42$ \\
Target height (SDS) & $-1.5 \pm 0.9$ & $-3.0 ; 0.2$ \\
Height (SDS) & $-2.7 \pm 0.5$ & $-3.7 ;-1.8$ \\
Weight (SDS) & $-1.9 \pm 0.7$ & $-3.4 ; 5.9$ \\
Height velocity (cm/year) & $4.7 \pm 0.7$ & $3.4 ; 5.9$ \\
Height velocity (SDS) & $-1.2 \pm 1.3$ & $-3.8 ; 0.9$ \\
CA (years) & $9.6 \pm 0.9$ & $7.1 ; 11.0$ \\
BA (years) & $7.7 \pm 1.3$ & $4.0 ; 10.0$ \\
BA retardation (CA-BA) (years) & $1.7 \pm 1.1$ & $-0.2 ; 3.7$ \\
\hline
\end{tabular}

*Adjusted for gestational age.

A significant increase in height SDS/CA was observed at the end of the 2 year treatment period, with an SDS change from baseline of $+1.3 \pm 0.3(P<0.001 ; 95 \%$ confidence interval (CI): 1.1 to 1.4 SDS). Patients had a mean height SDS of $-1.4 \pm 0.6$ (Fig. 2), which was very close to their mean TH $(-1.5 \pm 0.9$ SDS $)$, and $83 \%$ of patients had reached a height within the normal range for CA by the end of the 2 year treatment period. Preliminary analyses of these data have been previously published (28).

After the 2-year treatment period, patients were followed for 2 additional years without treatment. At the 4-year endpoint, change in height from baseline $(1.1 \pm 0.4$ SDS $)$ remained significant $(P<0.001,95 \%$ CI: 0.9 to 1.2 SDS), and $76 \%$ of patients had reached a height within the normal range for CA. However, the mean height had decreased significantly from $-1.4 \pm 0.6$ SDS at the end of year 2 to $-1.6 \pm 0.7$ SDS at the end of year $4(P=0.0073)$.

All children were prepubertal at baseline, and most of them entered puberty during Period I. By the end of the second year of the study, $46 \%$ of boys and girls had entered puberty, and this proportion increased to $93 \%$ of boys and girls by the end of the fourth year $(78 \%$ of the girls and $100 \%$ of the boys). Mean age at pubertal onset for the patients followed until the end of period I was $11.9 \pm 0.9$ years for boys $(n=21$; range: $10.0-$ 13.3 years $)$ and $10.5 \pm 0.8$ years for girls $(n=8$; range:

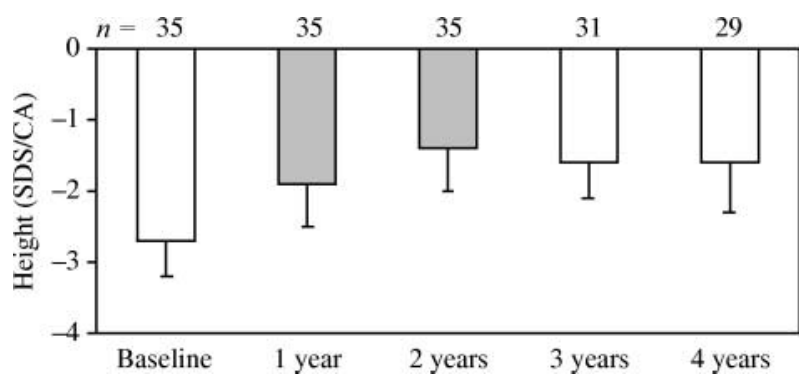

Figure 2 Height SDS for CA during Period I without ( $\square$ ) and with ( ) GH treatment. Significant level of change in height SDS vs baseline at 2 and 4 years; $P<0.001$.
8.6-11.1 years). Mean BA maturation progressed 2.3 years during the 2 years of treatment and 2.5 years during the subsequent 2 year off-treatment period.

IGF-I concentrations increased during hGH treatment from a baseline value of $0.8 \pm 0.3 \mathrm{IU} / \mathrm{ml}$ to $1.7 \pm 0.6 \mathrm{IU} / \mathrm{ml}$, and then to $1.5 \pm 0.4 \mathrm{IU} / \mathrm{ml}$, at the end of the first and second years of therapy respectively. These values remained stable at $1.4 \pm 0.6 \mathrm{U} / \mathrm{ml}$ during the third year of the study, despite the fact that patients were untreated.

Model for height gain at 2 years (Model 1) The model used to explain outcome after 2 years of hGH treatment is shown in Table $2\left(r^{2}=0.6\right)$. Lesser baseline BA retardation, greater baseline height velocity, and lower baseline IGF-I levels were associated with an increased height gain at 2 years. Other variables, including gender, gestational age, birth length, birth weight, weight, age at pubertal onset, age at baseline, TH, mother's height, father's height, and parental adjusted height SDS at baseline, were not associated with outcome in this model.

Model for height changes between years 2 and 4 (Model 2) The model used to explain height changes during the off-treatment period is shown in Table 3 $\left(r^{2}=0.75\right)$. Baseline weight and male gender were positively associated with height SDS changes, while baseline BA retardation and height SDS gain at 2 years were inversely correlated with height SDS changes between years 2 and 4 . As pubertal age is colinear to gender, it was not included in Model 2. Other variables not independently associated with height SDS changes during this period included TH, parental adjusted height SDS, height SDS, height velocity, mother's height, father's height, and IGF-I at baseline.

\section{Period II}

Height changes for patients entering Period II Twenty-four patients entered study Period II (starting at year 5 of the study): seven resumed hGH therapy

Table 2 Predictive factors for height gain in SDS at 2 years (Model 1). $n=24, r^{2}=0.60$.

\begin{tabular}{|c|c|c|c|}
\hline Variable & $\begin{array}{l}\text { Parameter } \\
\text { estimate }^{\dagger}\end{array}$ & $\begin{array}{l}95 \% \text { confidence } \\
\text { interval }\end{array}$ & $\boldsymbol{P}$ \\
\hline $\begin{array}{l}\text { BA retardation at } \\
\text { baseline (years) }\end{array}$ & -0.13 & $-0.23 ;-0.03$ & 0.0148 \\
\hline $\begin{array}{l}\text { Height at baseline } \\
\text { (SDS/CA) } \dagger\end{array}$ & -0.19 & $-0.34 ;-0.05$ & 0.15 \\
\hline $\begin{array}{l}\text { Height velocity at } \\
\text { baseline (cm/years) }\end{array}$ & 0.19 & $0.02 ; 0.35$ & 0.0373 \\
\hline IGF-I at baseline (IU/mI) & -0.74 & $-1.09 ;-0.39$ & 0.0007 \\
\hline
\end{tabular}

${ }^{\dagger}$ The regression coefficient represents the change in SDS per unit change in predictive variable. Height at baseline was maintained in the model as it may represent regression toward the mean. 
Table 3 Predictive factors for change in height SDS between years 2 and 4 (Model 2). $n=24, r^{2}=0.75$.

\begin{tabular}{lccc}
\hline Variable & $\begin{array}{c}\text { Parameter }^{\text {estimate }}{ }^{\dagger} \\
\text { interval }\end{array}$ & $\begin{array}{c}95 \% \text { confidence } \\
\text { ind }\end{array}$ \\
\hline $\begin{array}{c}\text { BA retardation at } \\
\text { baseline (years) }\end{array}$ & 0.07 & $-0.16 ; 0.03$ & 0.1878 \\
$\begin{array}{c}\text { Height gain at } \\
\text { 2 years (SDS/CA) }\end{array}$ & 0.52 & $-0.85 ;-0.18$ & 0.0072 \\
$\begin{array}{c}\text { Weight at baseline } \\
\text { (SDS/CA) }\end{array}$ & 0.27 & $0.07 ; 0.47$ & 0.0159 \\
Gender (male $=1)$ & 0.64 & $0.44 ; 0.84$ & $<0.0001$
\end{tabular}

${ }^{\dagger}$ The regression coefficient represents the change in SDS per unit change in predictive variable. According to Cook's laws of statistics (27), data from one patient were not included in this model.

(three girls and four boys), while 17 did not (four girls and 13 boys). For patients who resumed hGH therapy, mean height SDS remained stable until last height measurement $(-1.8 \pm 0.3$ SDS at year 5 vs $-1.7 \pm 1.0$ SDS at last height measurement), which occurred 7.1 \pm 1.0 years after baseline measurement and after an additional treatment duration of $1.6-0.8$ years (range: $0.5-2.4$ years). For patients who did not resume hGH therapy, height SDS decreased from $-1.8 \pm 0.7$ at year 5 to $-2.2 \pm 0.7$ at last height measurement, which occurred $7.4 \pm 0.9$ years after baseline measurement.

Adult height of 20 patients who reached adult height, four had resumed hGH therapy during Period II. For the adult height population, heights at the end of Period I were $-1.8 \pm 0.6$ and $-1.5 \pm 0.6$ SDS/CA for patients who resumed hGH therapy vs those who did not respectively. No difference in adult height was observed between the two groups $(-2.1 \pm 1.2$ and $-2.1 \pm 0.7$ SDS/age 18 for patients who resumed hGH therapy vs those who did not respectively). Adult heights were $0.7 \pm 1.2$ SDS below the respective THs for both groups. Both groups have been analyzed together thereafter for adult height and their characteristics and outcomes are summarized by gender in Table 4 . The overall height gains from baseline to adult height were $0.7 \pm 0.8$ SDS/CA and $0.5 \pm 0.8$ SDS/age 18 $(P=0.01 ; 95 \%$ CI: 0.1 to 0.9$)$. Height gain tended to be greater in girls than in boys $(0.7 \pm 1.1$ vs $0.4 \pm 0.7$ SDS/age 18, not significant). Height gain during puberty was $25.2 \pm 4.1 \mathrm{~cm}$ for the 12 boys and $21.3 \pm 3.9 \mathrm{~cm}$ for the eight girls.

Height SDS and predicted adult height SDS reached a maximum at year 2 in the adult height population (Fig. $3 \mathrm{a}$ and $\mathrm{b}$ ). When compared with predicted height at baseline (Fig. 3b), adult height improved significantly in girls (by $+1.2 \pm 1.1$ SDS/age $18(P=0.018)$ ) but not in boys $(+0.2 \pm 0.9$ SDS/age $18 \quad(P=N S)$. Altogether, $50 \%$ of these children reached an adult height within the normal range.

Model for gain at adult height (Model 3) In the final model (shown in Table 5), only three independent variables - BA at baseline, age at pubertal onset (S.D.), and baseline IGF-I - were found to be positively associated with adult height gain $\left(r^{2}=0.76\right)$. Other variables not significantly associated with adult height gain were parental adjusted height SDS, BA retardation, height velocity at baseline, weight at baseline, TH, father's height and mother's height.

Table 4 Characteristics of and outcomes for patients who were followed until adult height. Values are expressed as means \pm S.D.

\begin{tabular}{lrrr}
\hline & Boys $\left(n=12^{\dagger}\right)$ & Girls $\left(n=8^{\ddagger}\right)$ & Total $(n=20)$ \\
\hline At baseline & & & \\
CA (years) & $10.1 \pm 0.6$ & $8.9 \pm 0.6$ & $9.6 \pm 0.9$ \\
Height (SDS) & $2.6 \pm 0.4$ & $-2.6 \pm 0.6$ & $-2.6 \pm 0.5$ \\
Predicted adult height (SDS) & $-2.3 \pm 0.8$ & $-2.9 \pm 0.7$ & $-2.6 \pm 0.8$ \\
Target height (SDS) & $-1.4 \pm 1.0$ & $-1.4 \pm 0.7$ & $-1.4 \pm 0.9$ \\
Parental adjusted height (SDS/age 18) & $-1.2 \pm 1.2$ & $-1.2 \pm 1.1$ & $-1.2 \pm 1.1$ \\
During Period I & & & \\
Height at 2 years (SDS) & $-1.4 \pm 0.4$ & $-1.2 \pm 0.6$ & $-1.3 \pm 0.4$ \\
Height at 4 years (SDS) & $-1.3 \pm 0.4$ & $-1.9 \pm 0.7$ & $-1.5 \pm 0.6$ \\
At adult height measurement & & & \\
CA (years) & $18.0 \pm 1.10$ & $16.2 \pm 1.0$ & $17.3 \pm 1.3$ \\
Height (cm) & $161.2 \pm 3.7$ & $152.5 \pm 5.9$ & - \\
Height (SDS/CA) & $-2.2 \pm 0.6$ & $-1.7 \pm 1.0$ & $-2.0 \pm 0.8$ \\
Height - baseline height (SDS/CA) & $0.5 \pm 0.7$ & $0.9 \pm 0.9$ & $0.7 \pm 0.8^{\star \star}$ \\
Height (SDS/age 18) & $-2.2 \pm 0.6$ & $-1.9 \pm 1.1$ & $-2.1 \pm 0.8$ \\
Height - baseline height (SDS/age 18) & $0.4 \pm 0.7$ & $0.7 \pm 1.1$ & $0.5 \pm 0.8^{\star}$ \\
Height - predicted height at baseline (SDS/age 18) & $0.2 \pm 0.9$ & $1.2 \pm 1.1$ & $0.6 \pm 1.1$ \\
Parental adjusted height (SDS/age 18) & $-0.8 \pm 1.1$ & $-0.3 \pm 1.3$ & $-0.7 \pm 1.2$ \\
\hline
\end{tabular}

${ }^{\dagger}$ Two of 12 boys resumed hGH treatment.

${ }^{\ddagger}$ Two of eight girls resumed hGH treatment.

${ }^{\star} P=0.01 ;{ }^{*} P<0.001$. 

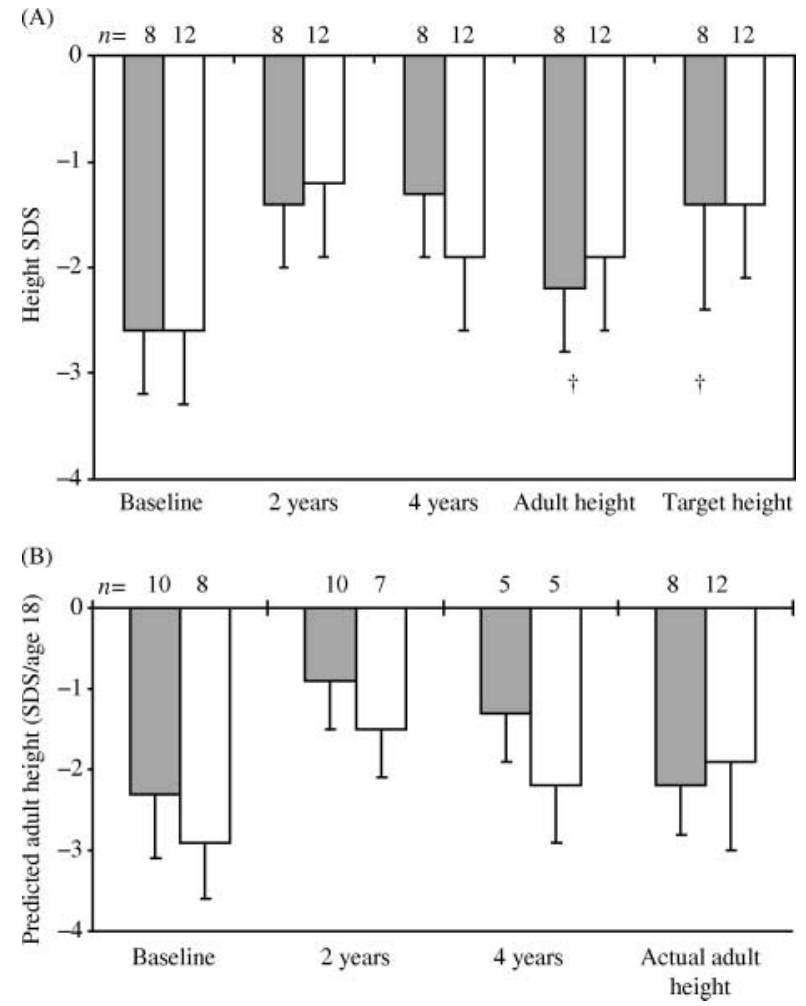

Figure 3 (A) Height SDS for patients who were followed until adult height $(n=20)$. (B) Predicted height SDS vs actual adult height for patients who were followed until adult height $(n=20,8$ girls and 12 boys). $\square$ boys; $\square$ girls. $\dagger$, adult height, predicted height and target height expressed as SDS/age 18.

\section{Adverse events}

Treatment-emergent adverse events and serious adverse events were reported for 30 and 13 patients respectively. One death from suicide occurred approximately 4 years after the patient had completed hGH treatment and was not considered by the investigator to be related to the study drug. The remaining adverse events reported during this study were typical for children and were not considered to be related to hGH treatment. Additionally, there were no relevant changes in clinical laboratory parameters that were considered to be related to hGH treatment. In particular, neither fasting blood glucose levels (baseline: $4.8 \pm 0.6 \mathrm{mmol} / \mathrm{l}$; at year 2: $4.6 \pm 0.5 \mathrm{mmol} / \mathrm{l} ; \quad P=0.132 / n=31)$ nor $\mathrm{HbA} 1 \mathrm{c}$ values (baseline: $4.9 \pm 0.5 \%$; at year $2: 5.1 \pm 0.6 \%$; at year $4: 5.1 \pm 0.3 \% ; P=0.078 / n=33$ ) were altered by hGH treatment. None of the children developed diabetes during the observation period (median $=5.2$ years, range: $1.9-9.4$ years).

\section{Discussion}

The present study addresses the short- and long-term effects of supra-physiological doses of hGH administered in late childhood to children with short stature born
Table 5 Predictive factors for gain of adult height (Model 3). $n=13, r^{2}=0.75$.

\begin{tabular}{lccc}
\hline Variable & $\begin{array}{c}\text { Parameter }^{\text {estimate }}{ }^{\dagger} \\
\text { interval }\end{array}$ & $\begin{array}{c}95 \% \text { confidence } \\
\text { interval }\end{array}$ \\
\hline $\begin{array}{l}\text { BA at baseline (years) } \\
\text { Age at onset of }\end{array}$ & 0.37 & $-0.10 ;-0.64$ & 0.008 \\
puberty (S.D.) & 0.64 & $0.35 ; 0.93$ & $<0.0021$ \\
$\begin{array}{l}\text { IGF-I at baseline } \\
\text { (IU/ml) }\end{array}$ & -1.19 & $-2.09 ;-0.30$ & 0.0284 \\
\hline
\end{tabular}

${ }^{\dagger}$ The regression coefficient represents the change in SDS per unit change in predictor.

SGA. A significant increase in height SDS was achieved after 2 years of treatment, bringing the patients close to their respective THs. During the period of treatment discontinuation (study years 2-4), the initial catchdown observed was of limited magnitude, and twothirds of the patients maintained a height within the normal range.

The present study is particularly valuable since it reports adult heights in 20 out of 35 children included in the trial. The gains in adult height compared with baseline were $0.7 \pm 0.9 \mathrm{SDS} / \mathrm{CA}$ and $0.5 \pm 0.9 \mathrm{SDS} /$ age 18 for the adult height population. This modest result, which was achieved after a mean treatment duration of less than 3 years and after discontinuation of treatment several years before adult height measurement for $80 \%$ of the cohort, has questionable clinical significance and raises the question of the role of hGH treatment vs spontaneous catch-up. However, the design of the study with discontinuous therapy aimed at testing the effect of a relatively limited exposure to $\mathrm{hGH}$, with attention to comfort for the patient, safety and overall costs of treatment. Therefore, our results have to be interpreted in the context of this framework if compared with other studies summarized in Table 6.

The results of this study after 2 years of hGH therapy are consistent with those described in studies in which a similar hGH dosage was used $(7-10)$. The unique feature of the current study compared with long-term studies published in the literature $(14-16,18)$ was the discontinuous treatment design, as most of the children were treated for 2 years and were then followed (untreated) until they had reached adult height. A limited number of children $(n=7)$ received hGH for a second treatment period, which led to a total treatment duration of more than 3 years. However, their number was too small to have an impact on the results as a whole.

The absence of an untreated control group precludes definite conclusions regarding the impact of the limited hGH treatment period in this study on adult height, since the relatively small gain in height SDS at adult height may have been attributable to spontaneous catch-up growth.

When the trial was designed, a randomized control group was not considered feasible by investigators 
Table 6 Comparison of adult height data from studies in the literature.

\begin{tabular}{|c|c|c|c|c|c|}
\hline Reference & $n$ & $\begin{array}{l}\text { Mean age at study } \\
\text { inclusion (years) }\end{array}$ & $\begin{array}{l}\text { hGH dosage } \\
\text { (mg/kg/day) }\end{array}$ & $\begin{array}{l}\text { Duration of observation or } \\
\text { of hGH treatment (years) }\end{array}$ & $\begin{array}{l}\text { Adult height } \\
\text { gain (SDS) }\end{array}$ \\
\hline Carel et al. 2003 (15) & 33 & $12.9 \pm 1.4$ & Untreated & 6 to 7 & $0.5 \pm 0.8^{*}$ \\
\hline Zucchini et al. 2001 (16) & 20 & $10.7 \pm 0.6$ & Untreated & NA & $0.1 \pm 0.1$ \\
\hline Coutant et al. 1998 (18) & 40 & $10.0 \pm 3.4$ & Untreated & $4.6 \pm 2.5$ & $0.6 \pm 0.9^{*}$ \\
\hline Van Pareren et al. 2003 (14) & 15 & 7 to 8 & Untreated & $7.5 \pm 1.2$ & $0.3 \pm 0.7$ \\
\hline Coutant et al. 1998 (18) & 70 & $10.0 \pm 2.5$ & 0.02 & $4.6 \pm 2.5$ & $1.0 \pm 0.8^{*}$ \\
\hline Van Pareren et al. 2003 (14) & 28 & $7.9 \pm 1.9$ & 0.03 & $7.9 \pm 1.7$ & $1.8 \pm 0.7$ \\
\hline Albanese et al. 1998 (17) & 12 & $7.6 \pm 2.1$ & 0.05 & 8.5 & $1.5 \pm 0.3$ \\
\hline Carel et al. 2003 (15) & 91 & $12.6 \pm 1.5$ & 0.067 & $2.7 \pm 0.6$ & $1.1 \pm 0.9 *$ \\
\hline Van Pareren et al. 2003 (14) & 54 & $8.2 \pm 1.9$ & 0.067 & $7.5 \pm 1.7$ & $2.1 \pm 0.8$ \\
\hline Current study & 20 & $9.6 \pm 0.9$ & 0.067 & $2.3 \pm 0.7$ & $0.7 \pm 0.9$ \\
\hline
\end{tabular}

$\mathrm{NA}=$ not available

* Studies with results expressed in SDS/age 18

and ethics committees. Therefore, it was originally planned to compare the patients in this study with a historical control group of patients selected in the mid-1980s. However, when the analysis was performed, major baseline differences, such as older age, lower birth length, or onset of puberty before the beginning of the observation ( $25 \%$ of patients in the historical control group), became obvious, and therefore, a comparison was deemed not to be appropriate. These patients have been described by Coutant et al. (18) and are referenced in Table 6.

Contradictory results regarding adult height in untreated patients - ranging from no catch-up growth $(14,16)$ to a mean spontaneous height gain of 0.5 SDS (15) or 0.6 SDS (18) - have been published (Table 6). One reason for these apparent discrepancies might be the variable age at inclusion of untreated patients. In the present study, children were included in the study at a mean CA of 9.7 years and were therefore closer to the onset of puberty than children in other studies $(14,17)$.

Sixty percent of the initial catch-up growth attained during hGH therapy was lost after treatment discontinuation, while the children in this study were followed up to adult height (mean loss of 0.5 SDS vs an initial height gain of 1.3 SDS). In comparison, patients who started hGH treatment in early puberty and who received a similar dose administered continuously for a mean of 2.7 years have shown greater height gains (15). The comparison of these two studies (15) and the current study) suggests that if hGH treatment is begun close to or during early puberty, it must be continued until adult height to ensure greater adult height gains.

Based on the multivariate analysis, the variability in height gain after 2 years of hGH treatment was best explained by BA retardation, height velocity and IGF-I levels at baseline. Children who grew faster during the first 2 years of the study had less pronounced BA retardation and greater height velocity at baseline.
Additionally, they were likely to enter puberty during the first 2 years of the study (almost $50 \%$ of children were Tanner stage 2 at the end of year 2), as expected considering the mean age of the children at study entry. Patients with lower baseline IGF-I levels attained greater adult heights. As GH deficiency (GHD) was excluded before study entry, this finding suggests that for a given auxological (height SDS/CA) and maturational status (BA and pubertal stage), low IGF-I levels at baseline indicate a greater potential to respond to exogenous GH. This finding is similar to that reported for patients with GHD (29).

Mean age at onset of puberty was normal for the patients in the study, consistent with what has been observed in other studies with hGH treatment $(9,10$, $12,14,30)$, despite the fact that untreated SGA children have been reported in the past to have an earlier onset of puberty than normal children $(19,31,32)$. The multivariate analysis in this study revealed that children who were older at the onset of puberty had a greater height gain at adult height. This finding, which goes against what is known about growth, is probably due to the fact that most of the children entered puberty during the first 4 years of the study. In comparison, van Pareren et al. (14) did not identify age at onset of puberty as an important parameter in their prediction model for adult height.

No disturbance in glucose metabolism was observed, during either hGH treatment or the follow-up period. This is reassuring, although the size of the sample studied and the duration of follow-up cannot exclude longterm effects on glucose metabolism. Most adverse events were characteristic for a population composed of children, and were unrelated to hGH treatment.

In conclusion, the short-term beneficial effects of high-dose hGH treatment observed in the present study were not sustained at adult height in most patients, probably due to the discontinuous pattern of hGH administration. Our present results are complementary to other evidence accumulated on hGH 
treatment in similar patient populations. In particular, they point to the need for a better evaluation of the spontaneous growth potential and long-term response to treatment in order to individualize treatment decision and protocol, aiming at further improvement of the overall outcome.

\section{Acknowledgements}

This work was sponsored by Eli Lilly and Company. JC Carel and JL Chaussain have received investigator fees from Lilly for this trial. E Ecosse has received a fee from Lilly for the statistical analysis work carried out.

The authors wish to thank all contributing investigators of the 0908 Lilly Study Group from the seven centers in France (P Chatelain and P Berlier, Lyon; M Colle, Bordeaux; C Jeandel and B Leheup, Nancy; Y Lebouc and S Cabrol, Trousseau Hospital, Paris; R Rappaport, Necker Hospital, Paris; M Tauber and C Pienkowski, Toulouse; and J-E Toublanc, St Vincent de Paul Hospital, Paris), as well as the Clinical Research staff of Lilly France (Nathalie Martin). We also wish to thank Gordon B Cutler Jr, Werner F Blum and Heike Jung for detailed critical review of the manuscript, and Anne M Wolka for editorial assistance.

\section{References}

1 Karlberg J \& Albertsson-Wikland K. Growth in full-term small-forgestational-age infants: from birth to final height. Pediatric Research 199538 733-739.

2 Hokken-Koelega ACS, de Ridder MAJ, Lemmen RJ, Den Hartog H, de Muinck Keizer-Schrama SMPF \& Drop SLS. Children born small for gestational age: do they catch up? Pediatric Research $199538267-271$.

3 Leger J, Levy-Marchal C, Bloch J, Pinet A, Chevenne D, Porquet D, Collin D \& Czernichow P. Reduced final height and indications for insulin resistance in 20 year olds born small for gestational age: regional cohort study. British Medical Journal $1997 \mathbf{3 1 5}$ $341-347$.

4 Fitzhardinge PM \& Inwood S. Long-term growth in small-for-date children. Acta Paediatrica Scandinaica 1989349 (Suppl) 27-33.

5 Lee PA, Chernausek SD, Hokken-Koelega ACS \& Czernichow P for the International Small for Gestational Age Advisory Board. International Small for Gestational Age Advisory Board consensus development conference statement: management of short children born small for gestational age, April 24-October 1 . 2001. Pediatrics 2003111 1253-1261.

6 Luo ZC, Albertsson-Wikland K \& Karlberg J. Length and body mass index at birth and target height influences on pattern of postnatal growth in children born small for gestational age. Pediatrics 1998102 E72.

7 Bundak R, Darendeliler F, Gunoz H, Bas F, Saka N \& Neyzi O. Growth hormone treatment in short children with intrauterine growth retardation. Journal of Pediatric Endocrinology and Metabolism 200114 313-318.

8 Czernichow P. Treatment with growth hormone in short children born with intrauterine growth retardation. Endocrine 200115 $39-42$.

9 de Zegher F, Albertsson-Wikland K, Wollmann HA, Chatelain P, Chaussain JL, Lofstrom A, Jonsson B \& Rosenfeld RG. Growth hormone treatment of short children born small for gestational age: growth responses with continuous and discontinuous regimens over 6 years. Journal of Clinical Endocrinology and Metabolism $2000852816-2821$.

10 Sas T, de Waal W, Mulder P, Houdijk M, Jansen M, Reeser M \& Hokken-Koelega A. Growth hormone treatment in children with short stature born small for gestational age: 5-year results of a randomized, double-blind, dose-response trial. Journal of Clinical Endocrinology and Metabolism 199984 3064-3070.

11 Fjellestad-Paulsen A, Simon D \& Czernichow P. Short children born small for gestational age and treated with growth hormone for three years have an important catch-down five years after discontinuation of treatment. Journal of Clinical Endocrinology and Metabolism 200489 1234-1239.

12 Albanese A \& Stanhope R. GH treatment induces sustained catchup growth in children with intrauterine growth retardation: 7year results. Hormone Research 199748 173-177.

13 Chaussain JL, Chatelain P \& Carel JC. The effect of long-term growth hormone treatment in children with short stature secondary to intrauterine growth retardation. Clinical Pediatrics and Endocrinology 19976 (Suppl 10) 123-127.

14 Van Pareren Y, Mulder P, Houdijk M, Jansen M, Reeser M \& Hokken-Koelega A. Adult height after long-term, continuous growth hormone $(\mathrm{GH})$ treatment in short children born small for gestational age: results of a randomized, double-blind, doseresponse GH trial. Journal of Clinical Endocrinology and Metabolism $2003883584-3590$.

15 Carel JC, Chatelain P, Rochiccioli P \& Chaussain JL. Improvement in adult height after growth hormone treatment in adolescents with short stature born small for gestational age: results of a randomized controlled study. Journal of Clinical Endocrinology and Metabolism $2003 \mathbf{8 8}$ 1587-1593.

16 Zucchini S, Cacciari E, Balsamo A, Cicognani A, Tassinari D, Barbieri E \& Gualandi S. Final height of short subjects of low birth weight with and without growth hormone treatment. Archives of Disease in Childhood 200184 340-343.

17 Albanese A, Azcona C \& Stanhope R. Final height in children with IUGR receiving GH treatment. Hormone Research 199850 (Suppl 3) Abstract P91.

18 Coutant R, Carel JC, Letrait M, Bouvattier C, Chatelain P, Coste J \& Chaussain JL. Short stature associated with intrauterine growth retardation: final height of untreated and growth hormone-treated children. Journal of Clinical Endocrinology and Metabolism 199883 1070-1074.

19 Sempe M, Pedron G \& Roy-Pernot MP. Auxology: Methods and Sequences. Paris: Theraplix, 1979.

20 Greulich WW \& Pyle SI. Radiographic Atlas of Skeletal Development of the Hand and Wrist, edn 2. Stanford, CA: Stanford University Press, 1959.

21 Usher R \& McLean F. Intrauterine growth of live-born Caucasian infants at sea level: standards obtained from measurements in 7 dimensions of infants born between 25 and 44 weeks of gestation. Journal of Pediatrics 1969 74 901-910.

22 Bayley N \& Pinneau SR. Tables for predicting adult height from skeletal age: revised for use with the Greulich-Pyle hand standards. Journal of Pediatrics $195240423-441$.

23 Blethen SL, Baptista J, Kuntze J, Foley T, LaFranchi S \& Johanson A. Adult height in growth hormone (GH)-deficient children treated with biosynthetic GH. The Genentech Growth Study Group. Journal of Clinical Endocrinology and Metabolism 199782 418-420.

24 Carel JC, Ecosse E, Nicolino M, Tauber M, Leger J, Cabrol S, BastieSigeac I, Chaussain JL \& Coste J. Adult height after long term treatment with recombinant growth hormone for idiopathic isolated growth hormone deficiency: observational follow up study of the French population based registry. British Medical Journal $200232570-77$.

25 Tanner JM \& Whitehouse RH. Clinical longitudinal standards for height, weight, height velocity, weight velocity, and stages of puberty. Archives of Disease in Childhood 197651 170-179.

26 Ranke MB. Towards a consensus on the definition of idiopathic short stature. Hormone Research 199645 (Suppl 2) 64-66. 
27 Kleinbaum DGG, Kupper LL, Muller KE \& Nizam A. Applied Regression Analysis and Other Multivariate Methods, edn 3. Pacific Grove, CA: Duxbury Press, 1998.

28 Rosilio M, Carel JC, Blazy D \& Chaussain JL. Growth hormone treatment of children with short stature secondary to intra-uterine growth retardation: effect of 2 years treatment and 2 years follow-up. Hormone Research $1997 \mathbf{4 8} 23-28$.

29 Schönau E, Westermann F, Rauch F, Stabrey A, Wassmer G, Keller E, Bramswig J \& Blum WF for the German Lilly Growth Response Study Group. A new and accurate prediction model for growth response to growth hormone treatment in children with growth hormone deficiency. European Journal of Endocrinology 2001144 13-20.

30 Boonstra V, van Pareren Y, Mulder P \& Hokken-Koelega A. Puberty in growth hormone-treated children born small for gestational age (SGA). Journal of Clinical Endocrinology and Metabolism $2003 \mathbf{8 8} 5753-5758$.

31 Davies PSW, Valley R \& Preece MA. Adolescent growth and pubertal progression in the Silver-Russell syndrome. Archives of Disease in Childhood 198863 130-135.

32 Tanner JM, Lejarraga H \& Cameron N. The natural history of the Silver-Russell syndrome: a longitudinal study of thirty-nine cases. Pediatric Research 19759 611-623.

Received 9 January 2005

Accepted 24 February 2005 